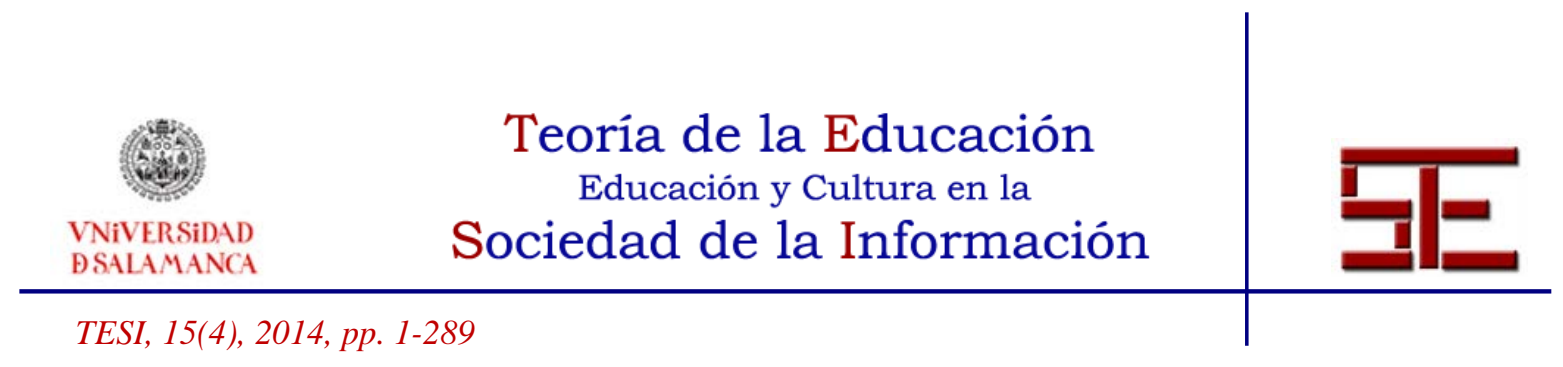

CONSTRUCTIVIST PEDAGOGY AT WORK IN A REALIST CLASSROOM. A CASE STUDY EXPLORING COLLEGE STUDENTS' ATTITUDES TOWARDS SCIENCE

\title{
LA PRÁCTICA DE LA PEDAGOGÍA CONSTRUCTIVISTA EN EL AULA REALISTA. UN ESTUDIO DE CASO QUE EXPLORA LAS ACTITUDES HACIA LA CIENCIA DE ESTUDIANTES DE GRADO
}

Ana JOFRE

OCAD University, Toronto, Canadá.

ajofre@ocadu.ca

\section{Stephanie MARIE MARI}

National Museum of Mathematics, Nueva York, EE.UU. stephaniemariemari@gmail.com

\begin{abstract}
:
This paper presents a case study of a physics-oriented liberal studies course on Science, Technology, and Society within the framework of constructivist pedagogy. We outline the challenges of using constructivist pedagogy to teach science, a subject whose philosophy is inherently realist. On the other hand, our case study demonstrates that a realist approach to pedagogy is not always the most effective way to teach science. While we are critical of constructivist philosophy, we also acknowledge that a constructivist approach to pedagogy can be effective in science education, as long as it is tethered to realism. The case study consists of three questions asked of 234 undergraduate students from two consecutive semesters. Their responses reveal the individual and cultural biases and the weak mathematics skills that may inhibit them from engaging in scientific thinking. The case study provides some support for applying constructivist pedagogy toward realist science education, and reveals the cognitive conflicts some students face when their pre-existing beliefs differ from what is being taught in the classroom as a universal reality. Our analysis of their responses explores the cooperating roles of realist philosophy and constructivist pedagogy.
\end{abstract}

Keywords: Pedagogy; Case study; Science Education; Constructivism; Realism; Science Technology and Society (STS).

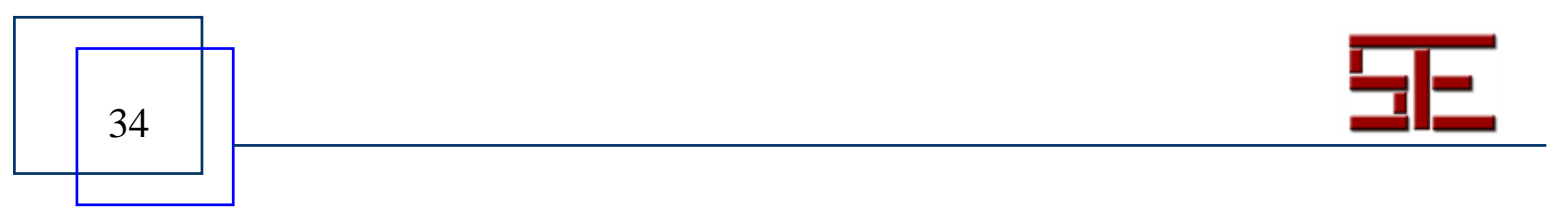




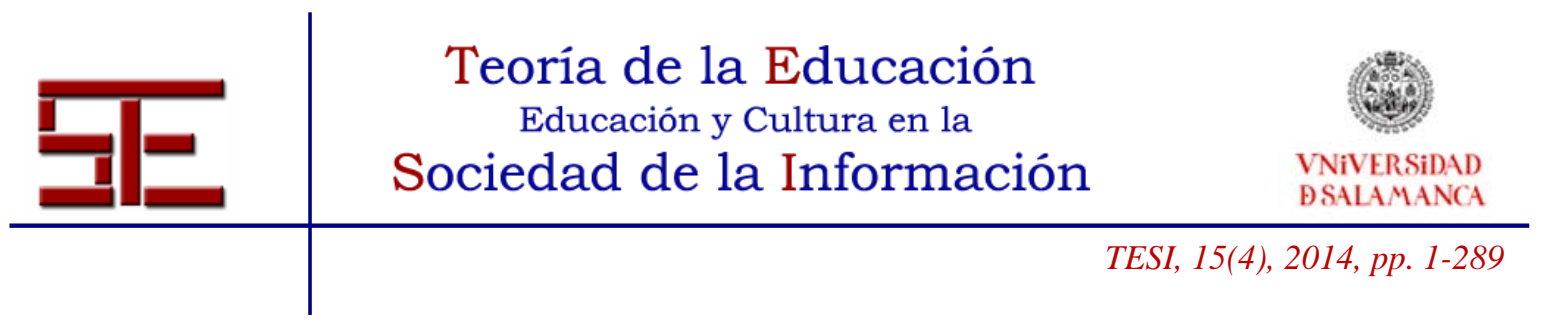

Resumen:

En este artículo se presenta un estudio de caso dentro del marco de la pedagogía constructivista del curso libre de orientación a la física Science, Techonology, and Society. Ponemos especial atención en los desafíos que conlleva el uso de la pedagogía constructivista en la enseñanza de la ciencia, una materia cuya filosofía es inherentemente realista. Por otro lado, nuestro estudio de caso demuestra que un enfoque realista de la pedagogía no es siempre la forma más efectiva de enseñar ciencia. Siendo críticas con la filosofía constructivista, reconocemos que un enfoque constructivista de la pedagogía puede ser efectivo para la educación científica, especialmente en la medida en que ésta queda sujeta a cierto realismo. El estudio de caso consiste en tres preguntas realizadas a 234 alumnos de grado durante dos semestres consecutivos. Sus respuestas muestran el sesgo individual y cultural, así como la escasa formación en matemáticas que pueden impedir que se sientan atraídos por el pensamiento científico. El estudio de caso proporciona apoyo para poner en práctica una pedagogía constructivista enfocada a una formación científica realista, y pone de manifiesto los conflictos cognitivos que enfrentan algunos estudiantes cuando las creencias previas difieren de lo que está siendo enseñado en el aula como una realidad universal. Nuestro análisis de las respuestas explora la labor colaborativa que puede establecerse entre la filosofía realista y la pedagogía constructivista.

Palabras clave: Pedagogía; Estudio de caso; Educación científica; Constructivismo; Realismo; Science Technology and Society (STS).

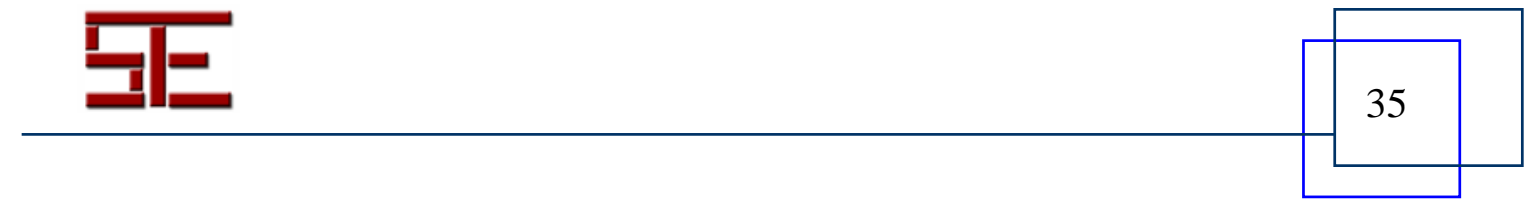




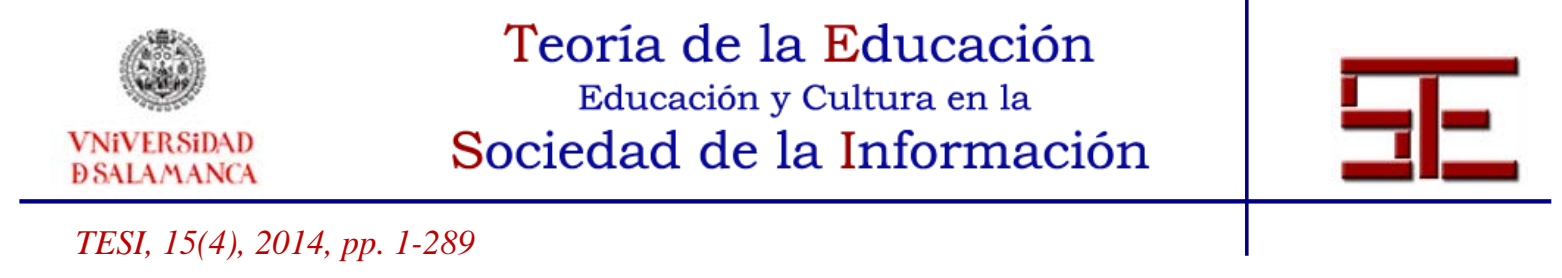

\section{INTRODUCTION}

There is a long-standing debate between the philosophies of constructivism and realism in scientific knowledge, and by extension, in the theory and practice of science education. However, these debates often conflate two different conditions constructivism as philosophy and constructivism as pedagogy (Jenkins, 2000). This is problematic because "what we call constructivism in science education has little to do with philosophical constructivism" (Gil-Pérez et al., 2002, 559). In this paper, we argue neither for the validity of scientific realism nor for the viability of constructivism, but we do observe that the defining purpose of science education - to disseminate scientific knowledge toward the goal of an aware populace -reflects a tacit acceptance of realism, as it is based upon the philosophical premise that there are universal scientific realities that exist in the natural world, specifically the set of approved facts and/or methods included in the curriculum. However, we do argue that constructivist pedagogy, despite constructivist philosophy's opposition to the notion of a universal scientific reality, provides a productive framework for helping students learn the set of scientific facts or methods that constitute a realist curriculum. We acknowledge the difficulty that exists in defining a precise nature of science (Irzik \& Nola, 2011), and so we limit the scope of our discussion to constructivism and realism as they apply to science education.

We use a case study of a physics-oriented liberal studies course on Science, Technology, and Society to demonstrate how constructivist pedagogy can be used to engage students in productive activities that constitute "doing science," toward the inherently realist goal of teaching them what scientists have done. The curriculum of the course included some fundamental conceptual principles of physics, as well as several perspectives on the philosophy of science with particular emphasis on distinguishing science from pseudoscience.We describe students' interactions with classroom assignments designed to help them construct personal understandings of science, including opinion surveys and problem-solving prompts which allowed/required them to discuss science from their own point of view or derive their own scientific method for estimation. Our analysis of their responses explores how students define and regard science, including the individual and cultural biases and weak mathematics skills that may inhibit or discourage them from engaging in scientific thinking. We also emphasize the roles that competing explanations -like those grounded in political, economic, or personal valuesplay in students' conceptions of science and perspectives on contemporary science policy issues. Our discussion of students' responses explores the cooperating roles that realist philosophy and constructivist pedagogy can play in science education.

Cole (1997) writes that constructivist philosophy in science education provides students with a framework to understand that scientists do not always agree, and that competing theories and paradigms may prevent scientific consensus. He also writes that constructivism acknowledges how scientists' working paradigms act as biases in

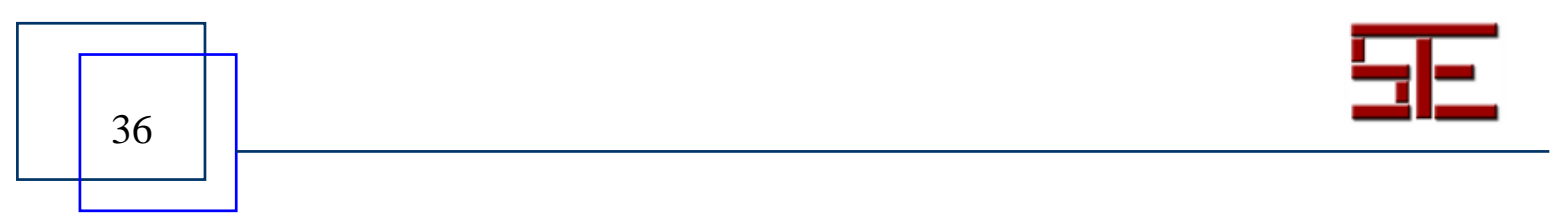




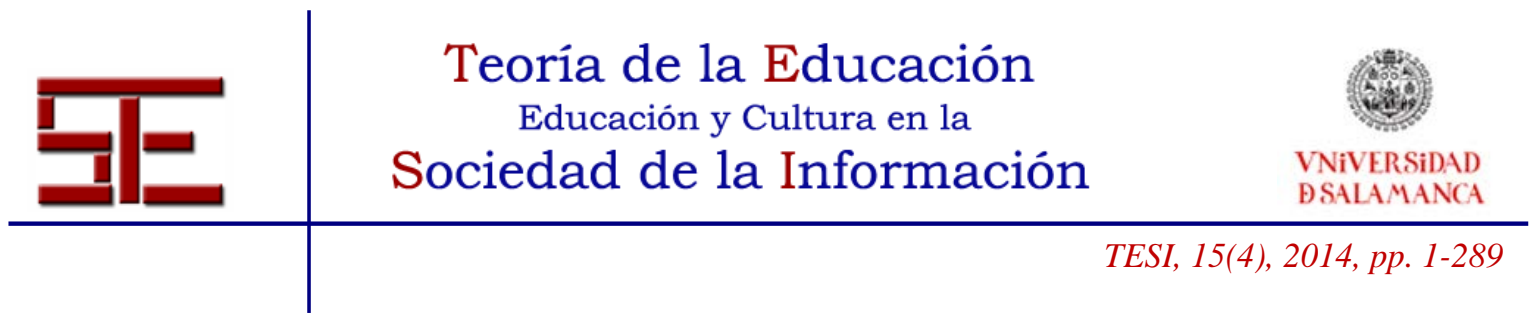

choosing problems to study and methods by which to study them. McCarthy and Sears (2000, 369) observe that "constructivism is often accepted without argument and without question as the view most appropriate for the science classroom," but argue that both moderate and radical versions of constructivism represent "seriously flawed" philosophies for science educators - and all educators. They write that science aims to teach students scientific knowledge and also to "articulate what science is," or to teach the philosophy of science. They assert that "science is not properly taught" if it is not taught from the perspective of scientific realism, and fear that constructivist science education may encourage students to hold on to "anti-scientific world-views". From their perspective, educating students in this way does them a "grave disservice" and "undermines the very science that we purport to teach" (Ibid, 376). Cole (1997) also voices concern that constructivist philosophy legitimizes non-scientific thinking, or thinking not based upon an observed/observable reality.

McCarthy and Sears (2000) note that public science education is shaped by constructivist philosophy, in part, to avoid personal and political discomfort when curriculum contradicts the pre-existing beliefs of students or parents. As an example of these occurrences, they offer the teaching of Darwinian evolution as 'just a theory,' no more or less accurate than any other, to satisfy parents and other community members who believe in creationism. Although evolution and climate change are concerned with very different subjects in science education, "critics of the teaching of evolution in the nation's classrooms are gaining ground in some states by linking the issue to global warming", making the argument that alternative (non-scientific) theories on both subjects have a place in public schools (Kaufman, 2010). Kaufman quotes Lawrence M. Krauss, physicist at Arizona State University, who argues that such efforts are "all about casting doubt on the veracity of science - to say it is just one view of the world, just another story, no better or more valid than fundamentalism”.

\section{CONSTRUCTIVIST PEDAGOGY IN COOPERATION WITH SCIENTIFIC REALISM}

\section{1.- The weaknesses of realism as science pedagogy}

While the philosophy of realism undergirds the teaching of science, given a curriculum containing knowledge purported to be scientific fact, realism may not represent an ideal pedagogical approach to sharing scientific knowledge and instilling the value of scientific curiosity. As Gil-Pérez et al. $(2002,563)$ argue, a weakness of a purely realist approach to education is that students are presented with science in its 'final' state, without social and historical context, and thus it may appear to learners that the knowledge has accumulated in a linear way, "ignoring crisis and deep restructurings"

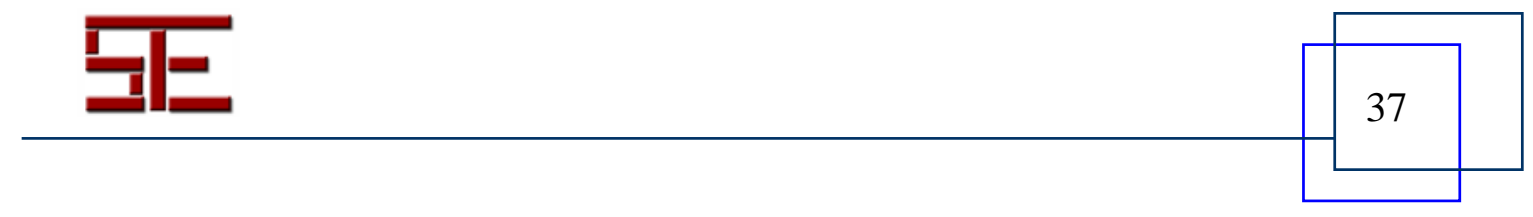




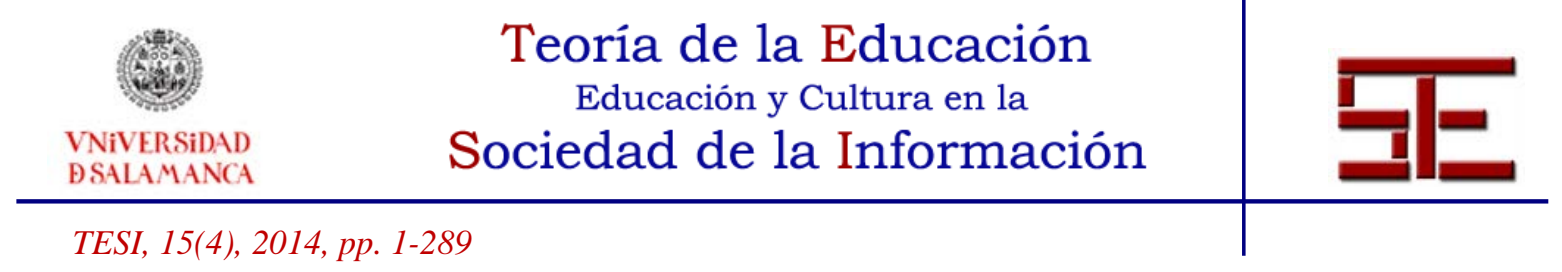

that occur due to paradigm shifts spurred by new discoveries. When described as a universal reality, scientific knowledge may be portrayed as 'common-sense' or 'obvious,' which can actually lead students toward non-scientific thinking, as science isn't about faith in 'common-sense' beliefs but about forming conclusions from observations. Scientific knowledge presented in this manner comes across as "veiled" and "elitist" to students, "hidden behind mathematical expressions" in such a way that it is rendered inaccessible (Ibid, 563). In textbooks, scientific discoveries are often portrayed as isolated activities conducted by 'great scientists' working alone, ignoring research teams and ongoing efforts that unite scientists across history and geography. Nola $(1997,79)$ writes that some constructivist educators argue that "objectivism adopts an authoritarian stance in science education and encourages passive learning" because it simply tells students which theory to believe. This "traditionalist" approach teaches science as an "acultural activity", whereas the "contextualist" teaching of science acknowledges the forces of society and culture that shape how knowledge is created, distributed, and diffused into various contexts (Koul, 2003, 115).

\section{2.- The strengths of constructivism as science pedagogy}

Although he argues that constructivist philosophy's focus on 'viability' has "lost the idea of a right and a wrong answer in science and science education,” Nola (1997, 79) asserts that constructivist pedagogy can be useful in the learning process - as long as realism is used to define the 'correct' answers students need to build a foundation for exploratory learning. He recognizes that knowledge cannot simply be transmitted to students by telling them the correct answer - it can be developed only when students "go through the steps of reasoning by themselves and thereby make fully explicit to themselves the reasons for the correct answer" (Ibid, 59). Constructivist pedagogy does not conflict with realist philosophy because, as Jenkins $(2000,601)$ argues, engaging students in the active process of constructing knowledge does not reject the existence of an external reality.

A constructivist approach to learning promotes the consideration of students' interest in and evaluation of the worthiness of the knowledge, giving meaning to their learning efforts. It also calls attention to the pre-existing knowledge that students bring to the classroom, beliefs that teachers must take into account if the transmission of new knowledge is to be successful (Gil-Pérez et al., 2000; Jenkins, 2000). Koul (2003, 118) writes that "two modes of thinking - empirical and non-empirical - compete with another to shape children's conceptualizations" and that pre-existing knowledge (religious teachings, for example) may "guide and constrain the types of inferences a student makes about reality". Values promoted in the family and in the wider culture influence the ideas that young learners develop toward physical and metaphysical realities. Given these competing influences, it does not infrequently occur that students'

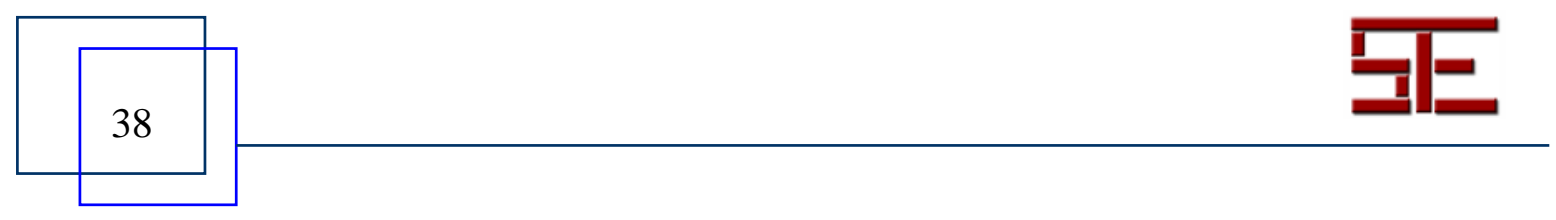




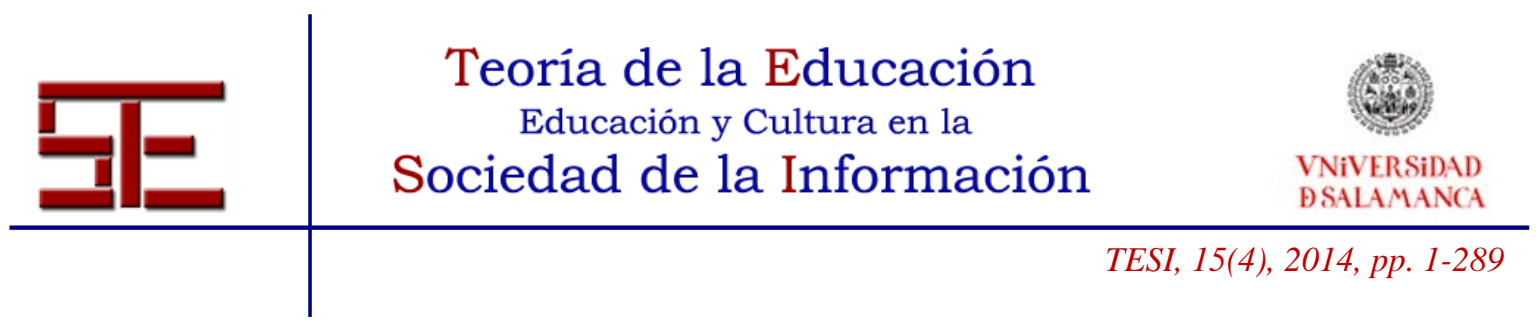

existing ideas include incorrect (according to the curriculum) understandings of natural phenomena.

What are educators to do in these situations? Jenkins $(2000,605)$ writes that even philosophically constructivist science teachers are likely to be dismayed when students, after being presented with overwhelming scientific evidence, "retain erroneous 'commonsense' or 'everyday' understandings" of the natural world. These situations require students to resolve a "cognitive conflict” between their own understandings of a problem and the scientific knowledge presented as universal reality. Gil-Pérez et al. (2002) write that, in a constructivist science classroom, cognitive conflicts (differences between a student's pre-existing knowledge and the information presented as fact in the curriculum) are framed as a confrontation between different hypotheses, not between correct and incorrect beliefs. Gil-Pérez et al. argue that it isn't productive for a teacher to solicit a range of student opinions, then dismiss all those but the ones that conform to scientific consensus; to do so would discourage open dialogue. From this perspective, if a student holds a belief that departs from the one promoted by the textbook or teacher, neither party is wrong and both constructions of knowledge are potentially viable.

Such a view is problematic for teaching science because viability does not constitute scientific knowledge. The scientific process compares our explanation or prediction to unbiased observations of the natural world. If a theory or hypothesis passes the tests to which it is subjected, only then can we tentatively consider it knowledge.

\section{3.- Constructivist pedagogy to help students "make sense" of science}

Hutchinson and Hammer (2010, 508) explore students' epistemological framing of science -that is, "how students understand their own activity with respect to knowledge and learning”. Epistemological framing describes how learners generalize knowledge from previous experiences to make sense of subsequent situations perceived as similar. Frames are used to explain to ourselves and others what is going on, and thus dictate the concepts we use to describe our observations and conclusions. Frames are used to answer questions like 'What is happening here?' and 'What is expected of me?' and thus shape our expectations and experiences, including the choices we make in a situation.

Using their previous experiences, students typically frame science education in two major ways - making sense of natural phenomena (which can be aligned with constructivist pedagogy), or playing the classroom game (which aligns with a realist approach to teaching and learning). When playing the classroom game, "students use sanctioned methods to produce answers, which then serve as a sort of currency to be exchanged for a grade” (Hutchinson \& Hammer, 2010, 508). In the classroom game, knowledge is transmitted directly from teacher/textbook to students. Students expect they will receive this knowledge, then be expected to reproduce it. In high school

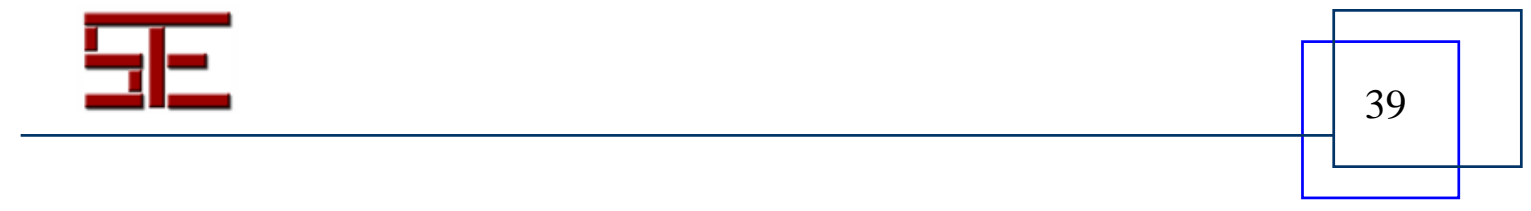




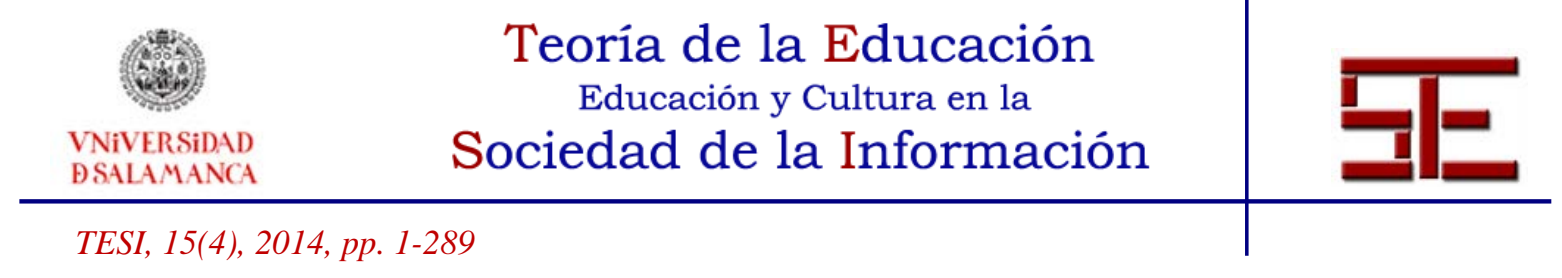

science education, the classroom game often plays out in a "triadic dialogue" between the teacher and students, involving a cycle of initiation (teacher asks a question), response (student produces a response), and evaluation (response is judged against criteria for correctness). Students come to understand they will achieve a successful evaluation only if they present the 'correct' answer in response; the knowledge they produce when playing the classroom game only 'counts' if it matches the universal reality represented in the answer key.

Hutchinson and Hammer view this as "unproductive framing," because students don't perceive their activities as about understanding science, but as "completing the steps required for a satisfactory grade” (Ibid, 507) They note that, given their previous experiences, students typically arrive in the science classroom focusing on unproductive framing.

In contrast, "productive framing" of science education involves activities that encourage students to make sense of natural phenomena scientifically, to draw scientific conclusions about the nature of the world (Ibid, 507). Students feel that what they learn in productive activities can be applied outside of the classroom. McCarthy and Sears (2000) write that such productive framing is often marked by students' use of informal terminology (rather than formal scientific terms), especially in introductory courses, as they make sense of the world to themselves and others in their own words. They write that students deal with knowledge differently when using science to "make sense" of the world around them, rather than just reproducing the expected answer (McCarthy and Sears, 2000, 510). This productive framing typically involves "engaging in classroom activities that mirror important aspects of professional science" emphasizing the constructivist aim of learning to 'do science,' rather than just learning 'science facts' (Ibid, 507).They note that "making sense" rather than "reproducing knowledge" is closer to the actual process carried out by scientists (as long as efforts to make sense are consistently and systematically applied).

In today's idealized science classroom, students are engaged in productive activities that support the constructivist themes of personal experience and an individual reality, and which provide learners with opportunities for experimentation and freedom of inquiry and expression. As Jenkins (2000) states, in elementary education, constructivist pedagogy is frequently employed in the form of classroom projects, the importance of which extend beyond the subject matter, such as the development of skills necessary for working in groups. A science educator might set up a theoretical or hands-on experience that allows/requires students to work independently from the instructor to construct a solution to a problem, and sometimes even the method they use to arrive at it. These experiences help students "learn by doing", and also function to move students from the position of having "blind faith" in what is taught to them as science, to personally experiencing some aspect of what is presented as a universal scientific reality.

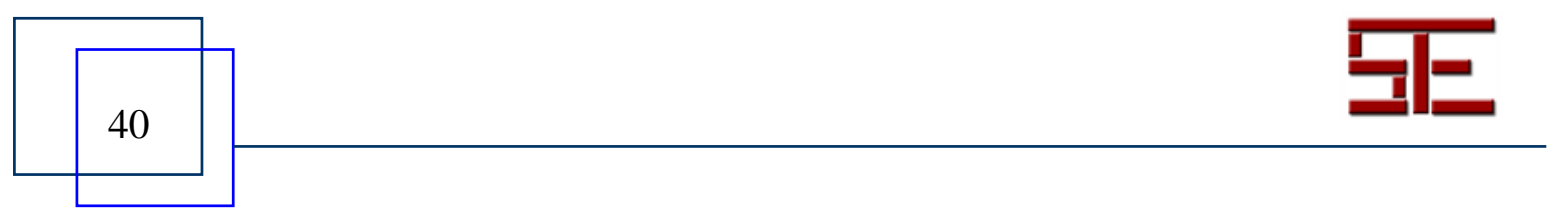




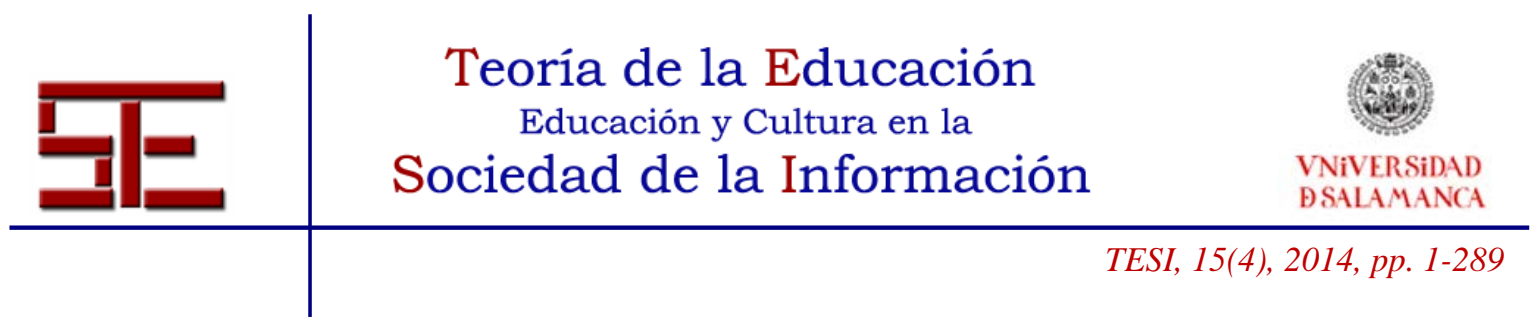

Data from the National Center for Education Statistics (NCES), published as The Nation's Report Card, provides some recent evidence suggesting that productive learning exercises - like those promoted by constructivist pedagogy, and unlike those associated with the realist classroom game - are correlated with higher levels of science achievement. The 2011 Report Card measured middle and high school students' achievement in core subjects, including science, based on a representative sample of 122,000 eighth grade students from 7,290 schools. Teachers reporting that students completed hands-on science projects every day or almost every day had students who "scored higher on average than students whose teachers reported students did hands-on projects in class less frequently" (NCES, 2012, 10). However, only 16\% of students were in classrooms that engaged in daily or almost daily hands-on learning. Fifty-six percent of students engaged in hands-on learning once or twice a week, $25 \%$ did so once or twice a month, and $2 \%$ never or hardly ever completed hands-on science projects.

Also measured was how often students worked together in groups to complete projects, noting that "teachers [who] reported that their students work together on science projects weekly or daily scored higher on average than students whose teachers reported that students did so monthly or never”. Of the students included in the data, $22 \%$ learned science in classrooms where they engaged in group work every day or almost every day, $47 \%$ worked in groups once or twice a week, and $29 \%$ worked on group science projects once or twice a month. Teachers of $2 \%$ of students reported never or hardly ever requiring students to work on group projects. They also polled students for responses to the following statement: "I do science-related activities that are not for schoolwork" (11). Students who agreed (25\%) or strongly agreed (4\%) tended to score higher than students who disagreed (46\%) or strongly disagreed (25\%).

\section{COURSE DESCRIPTION}

This case study was based on a course taught by Ana Jofre at a large research university located in the southeastern United States. The course, entitled "Science, Technology, and Society," exists as part of the university's general education requirement and sought to help students gain a functional understanding of science and the philosophy of science. Students were not required to complete any science or math units as a prerequisite, so the course was taught with no presumed science background. Here, we examine assignments completed by a total of 234 undergraduate students enrolled in two consecutive semesters.

In the course catalog, the description of the class noted that some basic physics principles would be covered; we speculate that this might have made the course attractive to students in STEM disciplines looking for "easy" credits, or students who otherwise felt confident in their basic science knowledge. Of the 234 students, 71

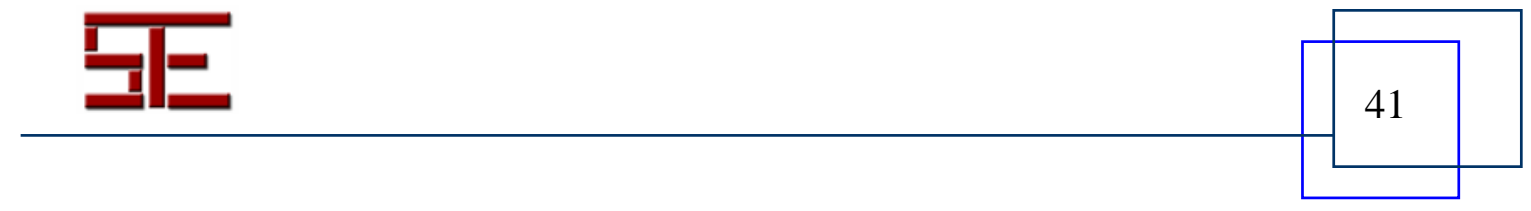




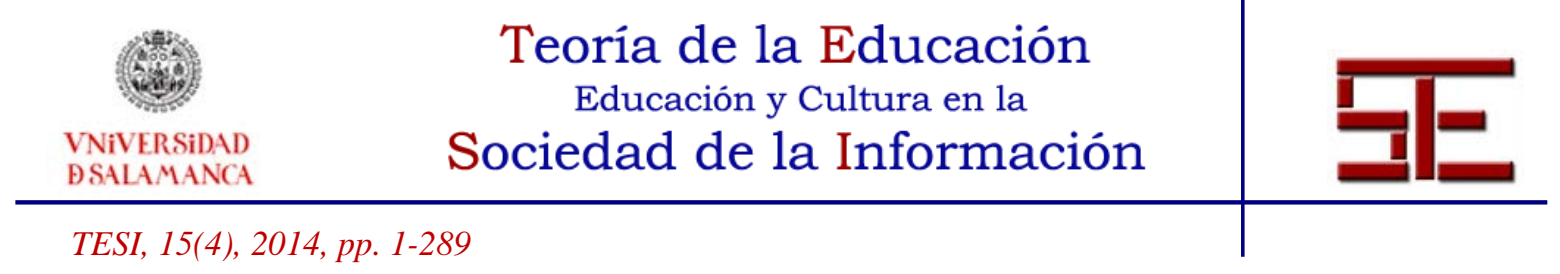

students were Engineering majors (30\%) and 34 had declared majors in Math or various Physical or Natural Sciences (14\%). However, many enrolled students were from nonSTEM disciplines (see TABLE 1).

About one third of enrollees -a total of 75 students- were formally undecided in their majors. This correlates with the sizable proportion of freshman students enrolled, about $49 \%$ (115 students); many students complete general education courses such as this one in their first year. Enrollees also included 74 sophomore students (32\%) and 26 juniors (11\%). Only 19 students categorized as seniors took the course (8\%). In both semesters, the enrollment was dramatically skewed toward male students. Of the 234 total enrollees, only 39 were female students (just $16 \%$ of the total).

TABLE 1: Students’ Majors

\begin{tabular}{|l|l|}
\hline DECLARED MAJOR & $\begin{array}{l}\text { NUMBER } \\
\mathbf{( \% )}\end{array}$ \\
\hline Undecided & $75(32 \%)$ \\
\hline Engineering & $71(30 \%)$ \\
\hline Math or Physical/Natural Science* & $34(14 \%)$ \\
\hline Liberal Arts/Social Science** & $18(8 \%)$ \\
\hline Business & $16(7 \%)$ \\
\hline Computer Science & $7(3 \%)$ \\
\hline Arts & $7(3 \%)$ \\
\hline Health/Human Services & $4(2 \%)$ \\
\hline Education & $2(1 \%)$ \\
\hline & \\
\hline TOTAL & $\mathbf{2 3 4}(\mathbf{1 0 0} \%)$ \\
\hline
\end{tabular}

* includes students with majors listed as Biology, Chemistry, Earth Sciences, Math, and Physics

** includes students with majors listed as Anthropology, Communications, Criminal

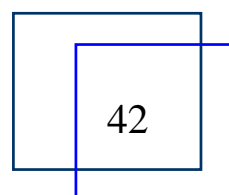




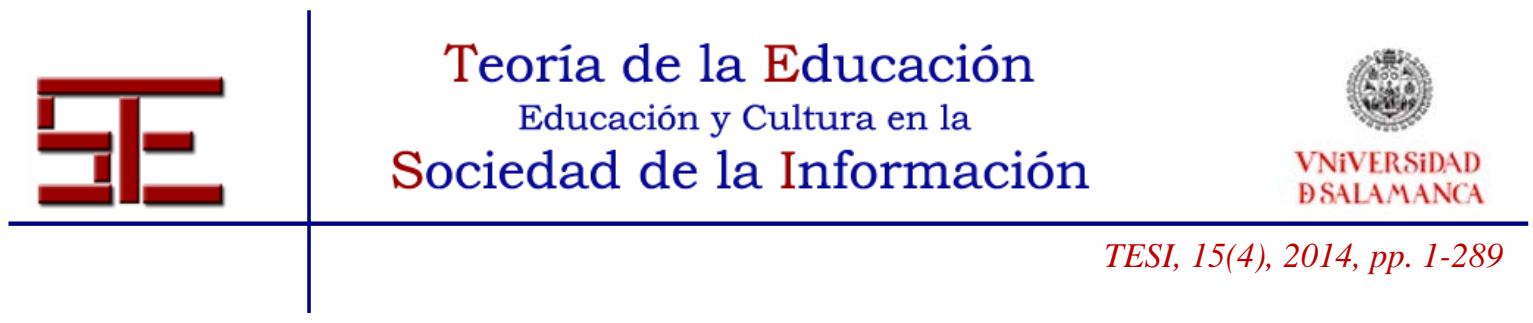

Justice, English, Geography, History, International Studies, Political Science, and Psychology

The main objectives for this course were for students to conceptually understand the basics physics relevant to social issues, and to gain a functional understanding of the philosophy of science, which requires learning what a scientific theory entails and learning to distinguish science from pseudoscience. The readings assigned to students included Voodoo Science: The Road from Foolishness to Fraud by Robert Park, Physics for Future Presidents: The Science Behind the Headlines by Richard Muller, and an excerpt from Carl Sagan's Boca's Brain: Reflections on the Romance of Science. As companions to these readings and other course assignments, students individually responded to prompts regarding their personal views of science. In this paper, we analyze the responses of one such question:

Q1) The precautionary principle states that scientific uncertainty should not be a reason to postpone measures to prevent harm. Do you think we should apply the precautionary principle to global warming? Explain why. Are your reasons economic, political, personal, or scientific?

This question was asked prior to instruction on the topic, in an effort to uncover the individual or cultural biases the students held toward science issues in public policy. The students were explicitly made aware of the multiple dimensions of the global warming problem (economic, political, personal, and scientific), and were invited to reflect on which aspects they valued. The answers to this question revealed students' pre-existing beliefs and a little about how these beliefs were constructed. Of particular interest to the researchers were the following questions: How prominently does science figure into the formation of their beliefs? If science figures prominently in their argument, does it manifest in a scientific approach to thinking or in an appeal to science as an authority?

Additionally, students responded to other questions, designed to examine the mathematical barriers that can inhibit or discourage scientific thinking:

Q2) Estimate the number of gumballs in the jar. (The students were shown a jar containing 100 gumballs).

Q3) How many atoms thick is a piece of paper? (The students were given measurements for paper and an atom).

While the two questions are mathematically similar, Question 3 is somewhat abstract, whereas Question 2 allows for a concrete hands-on experience. This set of questions was asked to explore the importance of the students' need to personally "make sense" of a problem in order to engage with it, or be capable of answering it correctly.

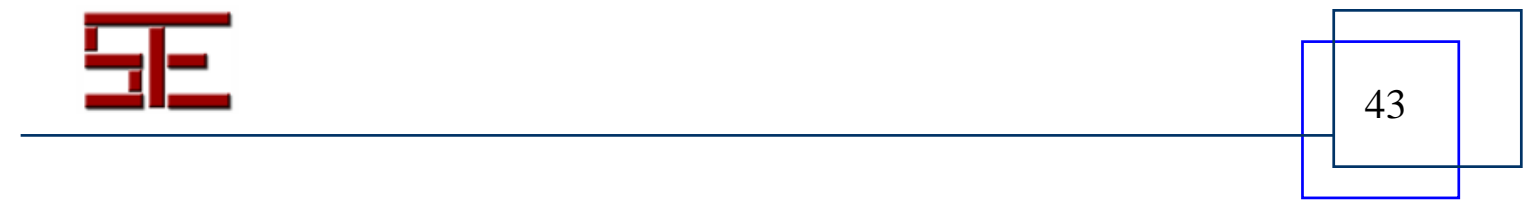




\section{\begin{tabular}{c} 
Teoria de la Educación \\
Educación y Cultura en la \\
$\begin{array}{c}\text { VNiVERSIDAD } \\
\text { BSALAMANCA }\end{array}$ \\
\hline TESI, 15(4), 2014, pp. 1-289
\end{tabular}}

\section{ANALYSIS OF STUDENTS RESPONSES}

Q1) Do you think we should apply the precautionary principle to global warming? Are your reasons economic, political, personal, or scientific?

Sixty-seven ( 56\%) of the 120 students who answered this question believed we should apply the precautionary principle to global warming. Of these 67 students, 40 cited observational evidence. Many students offered multiple lines of reasoning in their arguments for or against taking precautions, while some offered none, so the total number of reasons offered in support of their beliefs is greater than the total number of respondents. Twenty-nine supported their belief on the basis that the observations collected by climatologists indicate that global temperatures are rising in correlation with carbon dioxide levels in the atmosphere, three students cited the melting of polar ice, and eight cited increasingly severe natural disasters. These responses were drawn from scientific reasoning. Eight students supported their belief that action should be taken on global warming because pollution can degrade quality of life; these responses were drawn from personal reasoning, as they were based on individual experiences, like encounters with smog and litter.

In lieu of or in addition to observational evidence, 53 students cited specific consequences of not applying the precautionary principle to global warming. Eleven responses argued that we must take precautions on global warming in order to preserve Earth's natural resources for future generations. This involved personal reasoning, as many referred to the effects on their own children or grandchildren, with responses like "I would like my kids to enjoy nature as I have" and "I believe in leaving behind a better or the same world we have now for future generations".

Twenty-eight students stated that we must take precautions on global warming to control further damage to Earth. Twelve stated that applying the precautionary principle will encourage the development and use of alternatives to (finite) fossil fuels, with responses like "you'll eventually run out of [coal and oil], so why not just start working with renewable energies anyway?" and "finding other methods of energy will be beneficial in the long run, whether global warming is an issue or not". One student expressed the belief that "since large industries such as the oil industry and coal industry have a lot to lose if we start regulating the emissions of greenhouse gases, I do think that they might be trying to delay precautionary measures". These reasons were categorized as economic in nature, as they were concerned with the scarcity of resources - including time remaining to act, before irreversible damage is done.

Several students expressed the opinion that taking action now would be better than waiting for the problem to get worse, with responses like "even if the problem isn't as bad as scientists believe, it is better to be prepared and ready, than have it be too late"

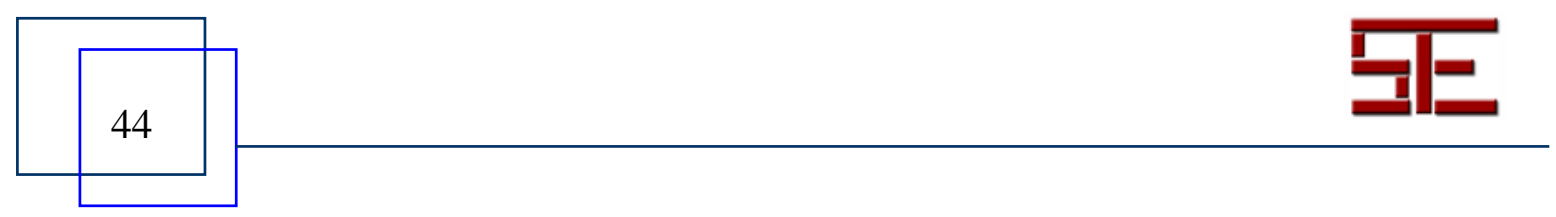




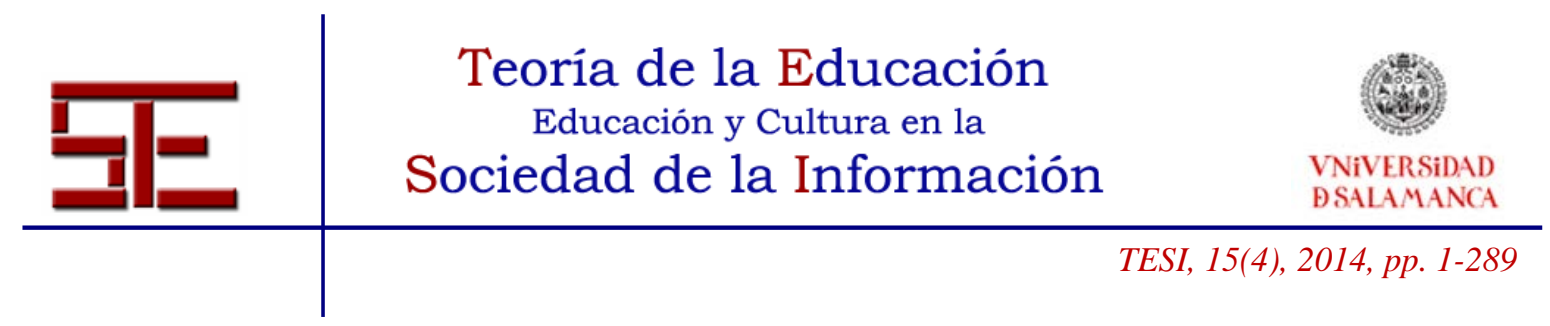

and "it would be a lot cheaper and easier to make changes to how we live now (even though it would still be very expensive), than if we had to make last minute changes in order to avoid a quickly approaching disaster”. Another wrote that it was imperative to take action now, even if the data was not conclusive: "By the time scientists are able to prove it definitively, we will most likely have gone past a point where we can stabilize our impact, much less reduce the impact we are having”.

Finally, 17 responses stated we should take precautions to control global warming because, in their opinion, there are no negative consequences associated with doing so. These responses, which argued that conserving resources is positive even if global warming isn't a threat, were also based on economic reasoning. These students expressed opinions like "treating our planet with respect should not only be a global warming thing" and "we shouldn't have to feel great danger before we start to care about the planet that we live on". None of the 67 students in support of taking action on global warming cited political reasoning.

Fifty-three students (44\%) believed we should NOT apply the precautionary principle to global warming. Of these students, 34 cited evidence supporting their belief that we should postpone measures to prevent harm. Although there is great consensus among climatologists regarding the existence and underlying causes of global warming, many students arguing against taking precautions used science-based reasoning but discarded the conclusions of experts. Several wrote that their rejection of global warming data was based on personal expertise, with responses like "I did a paper on global warming in high school" and "I'm just a regular college student and I can blow shotgun-sized holes in the argument". One student rejected the data because he didn't "trust the government or some scientist”.

Sixteen argued that there is a lack of scientific evidence that global warming is actually a threat ("half a degree could be blamed on equipment error"). Seven argued that global warming is occurring but the changes are too minute to worry about, that the threat is exaggerated. One wrote that precautions should not be taken just to prevent "losing a little land to flooding", while another admitted that summer days in recent years have been hotter, but categorized these changes as "nothing too unbearable". Additional scientific reasoning applied by those opposed to taking precautions included 14 responses stating that global warming is not primarily caused by humans, but rather by naturally-occurring climate cycles like Ice Ages. Many students using this line of reasoning expressed the belief that - even if humans were causing global warming humans didn't need to worry about fixing it. One wrote that "this Earth has been around for way longer than people and has always kept its equilibrium. I just think that nature will repeatedly take care of itself and flourish like it always has". Another argued that "Earth is a living breathing organism. It has adapted over the course of millions of years and it will continue to adapt".

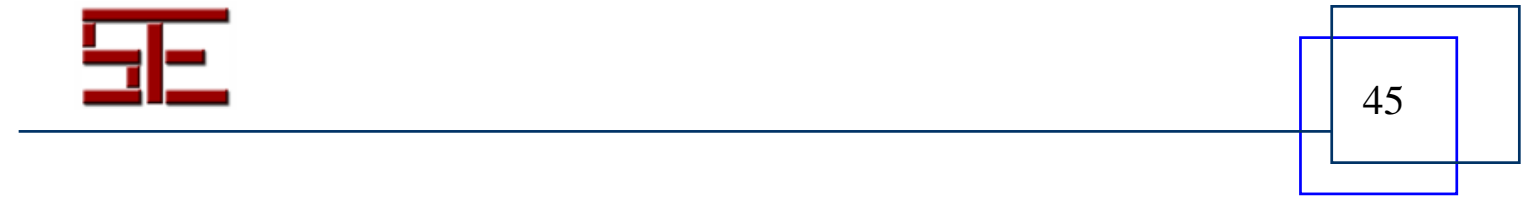




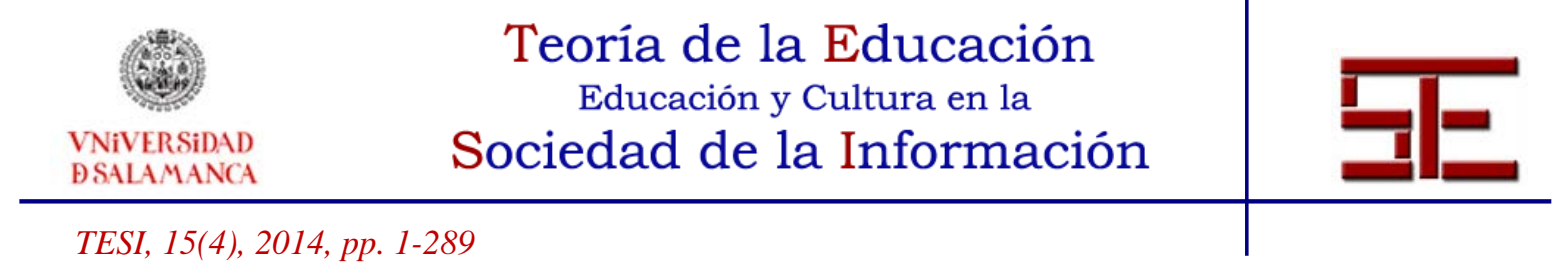

Seven students argued that awareness of global warming was politically motivated, not scientifically motivated. Some even mentioned specific politicians responsible for perpetuating the global warming claims they perceived as false. In rejecting the threat of global warming, one student wrote: "We should not use this principle because Al Gore does not use it. He has 2 houses, drives a Ford Explorer and his houses are powered by an electric company that burns coal for its power. Clearly he is not concerned, so neither am I. After all, he is the expert". Another student, referring to the "waste of money and resources" represented by electric cars like the Chevy Volt, blamed the car's manufacturing on pressure from President Obama.

Twenty-six students opposed to taking precautions cited negative consequences they believed would follow from taking such actions. Seventeen based these predictions on economic reasoning: we must not take precautions on global warming because doing so would be too expensive, could hurt the economy, and/or may cause disruptions in the food supply. Fifteen students applied personal reasoning, arguing that taking precautions on global warming would require a change of lifestyle and thus restrict personal freedoms.

Interestingly, several students rejected taking precautions based on global warming data, but still expressed personal support for environmentally conscious behaviors like recycling and picking up litter. One student wrote that "though pollution may not be a cause of global warming, it is still harmful to the air we breathe and it can just be ugly (i.e. smog or wrappers on a nature trail). Going green seems like a step in the right direction regardless of the idea of global warming”. Many of these responses were based on the value that it was good to "go green", but not by force: "If someone wishes to reduce their effect then they should. However, widespread enforcement or laws don't seem to me to be a good idea. Reduction in emissions is a good idea, but government mandates are not”.

\section{Q2) Estimate the number of gumballs in the jar.}

Responses from 205 students demonstrated the processes they used to estimate the number of gumballs in a jar. They were provided with the exact dimensions of the gumball (1" in diameter) and the jar (8.5” $\mathrm{H}$ x 3.5”W x 3.5”D). As the exercise was about estimating, students were also provided with rounded dimensions and encouraged to consider the gumball as a cube rather than as a sphere, to simplify volume calculations and to account for the empty space between stacked gumballs. They were also invited to visually examine both the gumballs and the jar. While the actual number of gumballs in the jar was 100, student responses ranged from 5.8 to 10,000. Measures of central tendency indicate that most estimates were very close to the actual number of gumballs. The mean response was 150 gumballs, with a median of 91 gumballs. The most frequent response submitted by students was 98 gumballs, a solution reached by 21 respondents. Of the 205 submitted responses, 184 ( 90\%) could be considered

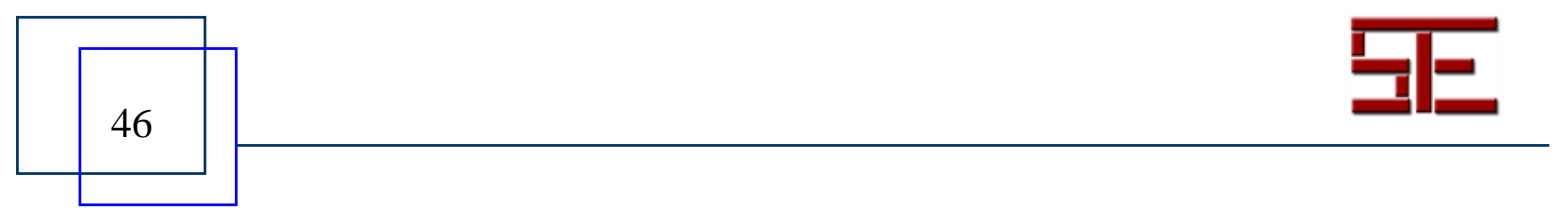




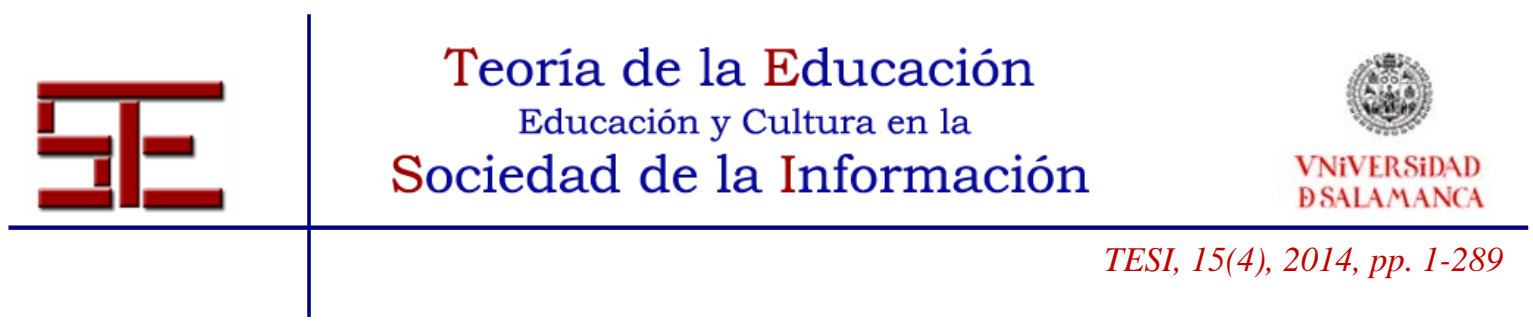

'correct'; while these students provided solutions of varying accuracy (as compared to the actual number of gumballs in the jar), they applied sound conceptual reasoning to the problem and/or their calculations were executed correctly.

The majority of students reached a correct conclusion by applying one of four methods. First, three students (2\%) calculated the number of gumballs in the jar by using the exact measurements provided to them, without rounding, to determine the volume of a single gumball and of the jar. They then divided the volume of jar by the volume of a gumball. It should be noted that students using this method did not adjust their calculations to account for the empty spaces between the stacked gumballs. Second, 85 students (41\% of all responses) calculated the number of gumballs in the jar by using the given rounded measurements to divide the volume of the jar by the volume of the gumball. A third method, applied by 74 students (36\%), involved a combination of both rounded and exact measurements. These students used the given rounded dimensions of the jar to calculate the container's volume, and then divided that by the exact (not rounded) volume of a gumball. Finally, and most interestingly, 22 students (11\% of responses) calculated the number of gumballs in the jar by estimating the number of gumballs in a single layer, using the given rounded dimensions of the gumball. This number was then multiplied by an estimated number of layers, based upon the height of the jar.

As stated above, about $90 \%$ of the submitted responses could be considered 'correct' based upon the reasoning applied and/or the calculations executed. However, some students arrived at a 'correct' answer even after making conceptual or calculation errors. In total -including those arriving at both 'correct' and 'incorrect' solutions- 76 students demonstrated errors in their math. Thirty students made calculation errors; these included improper execution of the formula for spherical or cylindrical volume, the incorrect calculation of the radius from the diameter, and using incorrect measurements in application of the correct formula. Forty-six students made conceptual errors, which included using incorrect formulas, omitting measurements from the formula, and multiplying the volumes of the jar and gumball instead of dividing them.

Although students were instructed to demonstrate their method, seven students submitted only final responses, with no work shown. Another 33 students submitted final responses that were not directly drawn from the work shown; we hypothesize that, after completing their calculations, they evaluated their result as not feasible and decided to guess instead. Forty-three students, including both those arriving at 'correct' and 'incorrect' solutions, opted to draw diagrams to help them visualize the number of gumballs in the jar.

Q3) How many atoms thick is a piece of paper?

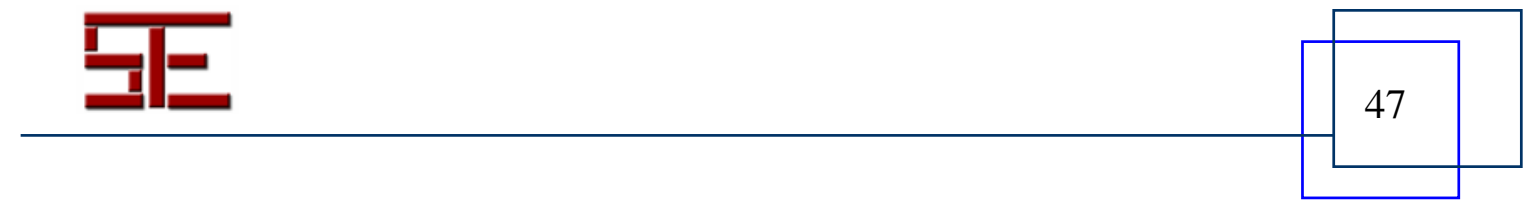




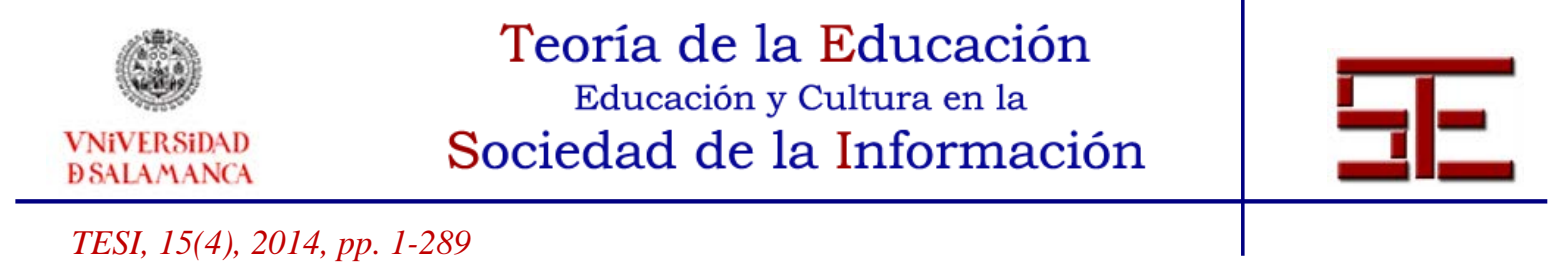

The students were given the approximate diameter of an atom, as well as the approximate thickness of a piece of paper in scientific notation in units of meters. To solve this problem, conceptually, students needed to understand that they should divide the thickness of the paper by the diameter of an atom. Out of 185 responses to this question, 92 students (50\%) correctly solved the problem while 93 students (50\%) did not. Of the 93 students who did not solve the problem correctly, 63 failed due to conceptual errors -their work demonstrated that they did not understand to divide the larger number (the thickness of the paper) by the smaller number (the diameter of the atom). Common conceptual errors included multiplying the two numbers instead of dividing them. Nineteen of the incorrect responses characterized by conceptual errors were labeled as such because students did not show their work or because the mathematical process they used was indecipherable. The other 30 students arrived at an incorrect solution due to calculation errors. They attempted to divide the larger measurement by the smaller one, but for a variety of (unknown) reasons, failed to complete the operation correctly.

\section{DISCUSSION OF STUDENT RESPONSES}

Our discussion below highlights the philosophical and pedagogical contexts of these activities, which allowed/required students to construct personal understandings within a problem space bounded by scientific realism. We describe how, while students were given freedom to make sense of the problems in their own ways, each activity included some aspect of a universal scientific reality that constrained the viability or validity of their responses. A few of the problems, especially those requiring some degree of mathematical correctness, presented a more constrained problem space, where students' solutions were compared against the solutions in line with the realist, universal laws that outline correct formulas and their correct execution.

The first question asked students their opinion on the precautionary principle, specifically if they thought the US should take action to prevent (further) global warming, even if we did not have all of the data on the threats associated with such a change in climate. This question, while based on an assumption of scientific realism global temperatures have been measured and there is consensus that they are risingused the constructivist pedagogical principle of taking into account students' preexisting beliefs. This perspective on teaching and learning encourages educators to provide students with opportunities for the individual analysis of data, allowing them to draw conclusions based on previous experiences and other sources of knowledge. Students were asked to specify what alternate bases -like those grounded in political, economic, or personal reasoning- they used to form their conclusions on the validity of scientific observations and predictions.

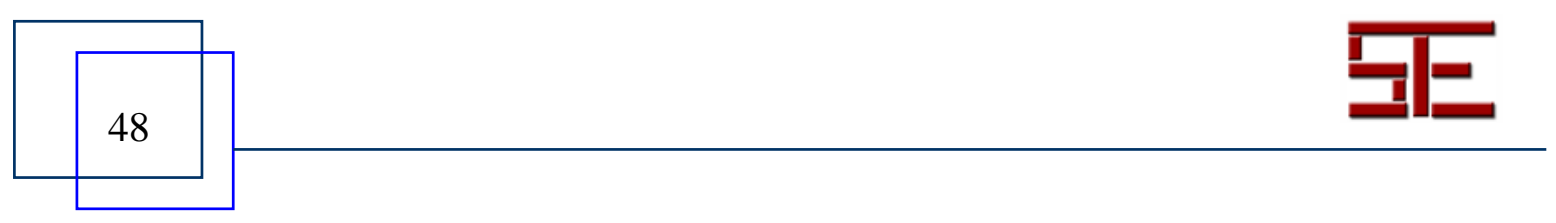




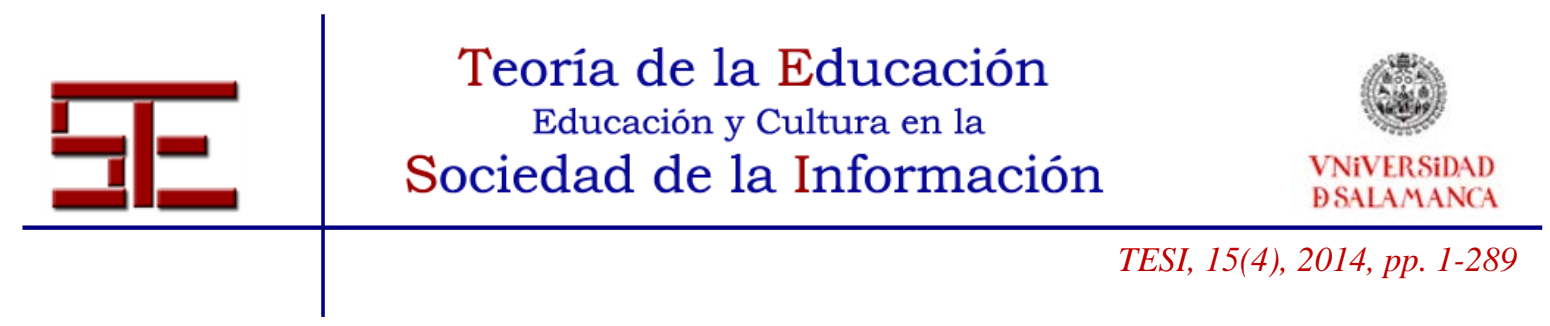

Many students were opposed to taking action on the threat of global warming, but did not eschew scientific reasoning in doing so, instead employing individual, alternate interpretations of the facts. For example, some students acknowledged that temperatures and sea levels were indeed rising, but personally minimized the significance of the changes or the consequences associated with them. Such dismissiveness is consistent with the reaction against warnings about the threats of global warming described by Feinberg \& Willer's (2011) study, which found that cautioning some people about the potentially disastrous consequences of global warming results in a decreased will to take action on climate change, because such dire warnings contradict a deeply held belief in a just and orderly world. Others simply did not believe in the data, framing scientific observations of rising global temperatures and sea levels as lies told by elected officials for political gain. Indeed, politics plays an important role in whether or not an individual accepts the scientific consensus on climate change. A study by Borick \& Rabe (2010) shows that partisan leanings strongly influence a person's beliefs regarding climate change and how they process information on the topic to draw their conclusions.

In the end, despite a science education curriculum that encourages them to trust in scientific data, students at all levels (especially young adults in college) are ideologically free to not 'believe in science'. However, it is important to note the role of constructivist philosophy in the assertion that belief equals knowledge. Students politically, economically, or otherwise personally opposed to (dealing with the consequences of) global warming used this type of individual, non-falsifiable reasoning to disregard decades of observations by trained scientists. Clearly, a realist approach to teaching climate change cannot change these pre-existing beliefs. A constructivist approach, on the other hand, may persuade students to accept the scientific consensus on climate change by relating scientific observations to their personal experiences. Recent studies (Egan \& Mullin, 2012; Akerlof et al., 2013; Joireman et al., 2010; Myers et al., 2012) show that personal experiences of climate change have a significant impact on belief in global warming.

The gumball estimation activity, Question 3, promoted constructivist inquiry within the constraints of realism, with a solution that could be achieved using a variety of methods. Students were presented with a problem with several tethered truths, including those provided by mathematical reality. They were given the exact physical dimensions of the container and the individual gumballs, but also encouraged to execute calculations with rounded values, for efficiency. They were primed to understand the way physics affected the filling of the container; they were told -and could see- how the gumballs stacked, leaving air space between each piece of candy that should be recognized in one's calculations. They could also personally derive their own knowledge from visual observations. While they could not actually extract and enumerate the contents of the container, students could (and did) get closer to the jar to examine the evidence,

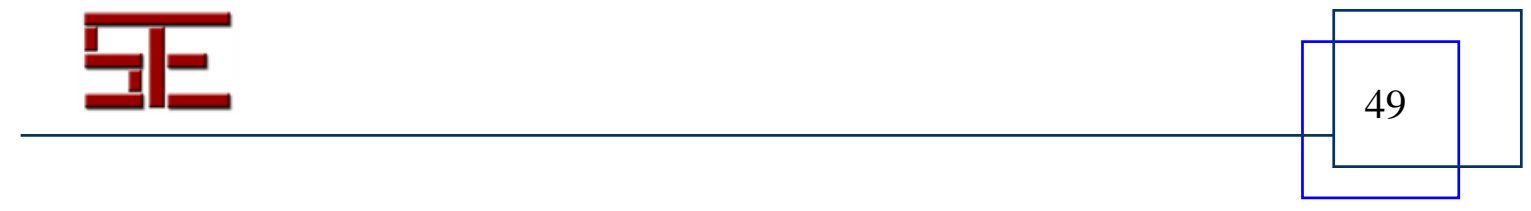




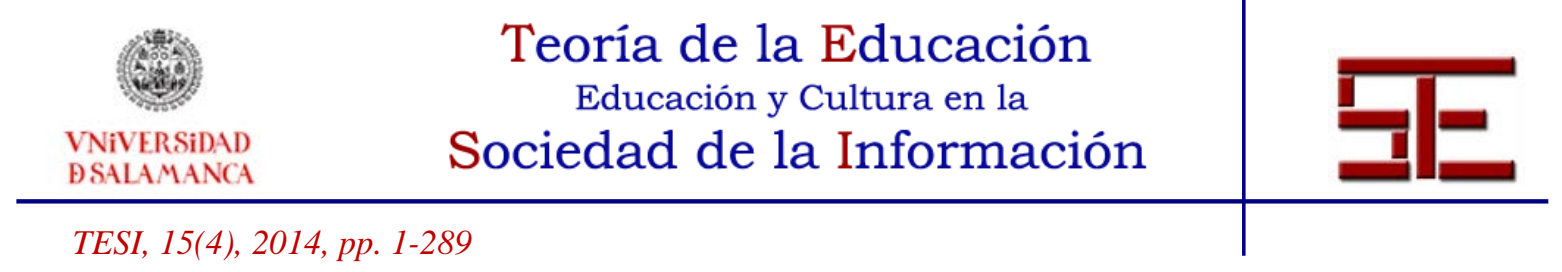

enabling them to better "make sense" of the problem with their own eyes.

Although there existed a true count of the gumballs inside, this assignment wasn't about scoring points in the classroom game, so answers did not need to be "textbook correct". The point of the activity -the way the instructor framed and hoped students would frame it- was productive, as making quick but accurate (due to their tether to reason) estimations is a valuable skill in many situations that arise inside and outside the science classroom. Furthermore, the burden of viability may be sufficient in some phases of a realist scientific process. For example, estimation may be 'good enough' for a working scientist's purpose, especially if their purpose is to convince themselves or others that it is worthwhile to pursue more valid calculations. However, some students were uncomfortable with the freedom allowed/required by this assignment -they were used to playing the classroom game, wanted to accrue points for being correct, and were reluctant to risk producing an invalid response. Despite this reluctance, nearly all students, regardless of their chosen method of calculation, eventually produced a viable estimate that placed them within reasonable distance of the actual number of gumballs, as demonstrated by measures of central tendency.

Finally, Question 3 asked students to estimate the thickness, in terms of the number of atoms, of a piece of paper (given the approximate diameter of an atom and estimated thickness of a piece of paper). This assignment was purely realist in nature: there existed a single correct answer and an infinite number of incorrect answers, according to the universal laws of mathematics. The correct answer could only be induced via one method, and this method required only one operation -one act of division. In those terms, this seems like a simple problem, one that nearly all university-level students should have been able to solve. But only half carried out the correct method and arrived at the correct solution. The other half arrived at an incorrect solution because they either executed the incorrect method, or made a calculation error when executing the correct method. Students who executed the incorrect method did so based upon some (false) pre-existing knowledge of how problems like this are solved; for example, some students multiplied the quantities instead of dividing. This question was highly realist anything other than just simple division, and a student would end up with an invalid answer. In this context, only the "textbook correct" response was valid. A solution to this problem could not be simultaneously invalid yet viable, because the students had no purpose or application for this knowledge other than participating in the classroom game -so there was no other function for which the knowledge could be fit (or not).

It was interesting to note how many more students were successful in answering the gumball question over the atom question. This is consistent with the difficulty students encounter when facing more abstract problems. Hoogland et al. (2012) found that students answer mathematical questions with more competency when the problems are enriched with meaningful imagery than when they are presented as word problems.

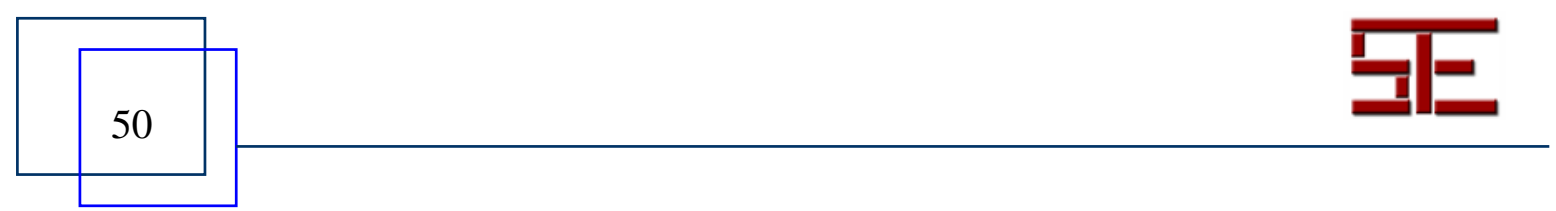




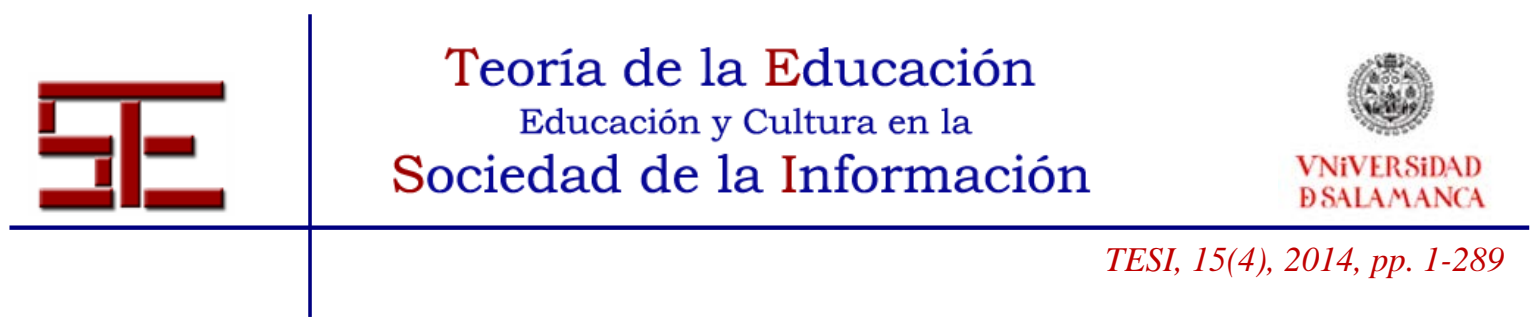

The other students who presented invalid responses to this problem did so because they made calculation errors in their execution of the correct process: they did the math wrong. They attempted to divide -they set the problem up correctly- but still arrived at an invalid answer. Why? Was the space of the problem too far outside their realm of realistic conception, preventing them from tethering it to pre-existing knowledge? Were the values confoundingly small or large? Perhaps students had such difficulty with this problem because they didn't have a frame for numbers of that scale, so they weren't able to apply an informed intuition toward an educated guess. The mathematical process could be checked (by inverting the operation), but the conceptual understanding (this many atoms stacked on top of each other) could not be made sense of through personal experience. However, it is important to note that in the realist classroom game, even students who solve the problem correctly by providing the single valid answer can do so without being able to personally make sense of the solution. Considered together, we assert that students' responses to these questions supports the idea that, while the practice of science education is strongly rooted in realist philosophy, a realist approach to pedagogy is not always the most effective way to teach science.

\section{CONCLUSIONS}

This research illustrates the cognitive conflicts some students face when their preexisting conceptions differ from what is being taught in the classroom. Such conflicts are particularly common in science policy issues that affect multiple domains; students may have constructed their pre-existing conceptions with reasoning based on other perspectives that are, indeed, relevant to the discussion. For example, while the observational data on global warming exists in the domain of science, applying global warming knowledge or taking action to stem the damage caused by global warming has political, economic, and personal components. As a result of these other components, a student's personal belief about the subject -and what actions should be taken on it- may differ from the scientific consensus. However, the purpose of science education should not be to teach students to "blindly" accept the scientific consensus, so we must take care to explore more effective ways of communicating scientific information to the public.

We believe this case study provides some support for applying constructivist pedagogy toward realist science education. Allowing students to construct their own path toward knowledge helps them better "make sense" of the knowledge, in their own words and in relation to their own experiences. Consider Question 2 (Estimate the number of gumballs in the jar) and Question 3 (How many atoms thick is a piece of paper?). The two questions are, mathematically, the same type of problem -to calculate the solution, divide the larger number by the smaller number- but students' experiences in solving them were very different. Question 2 provided more opportunity for students to interact

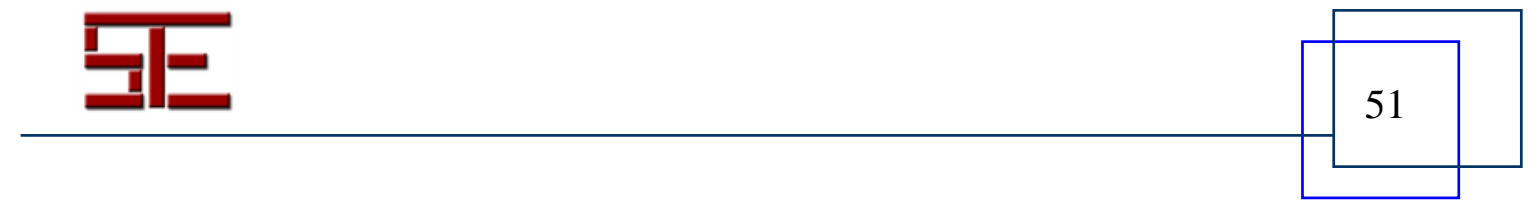




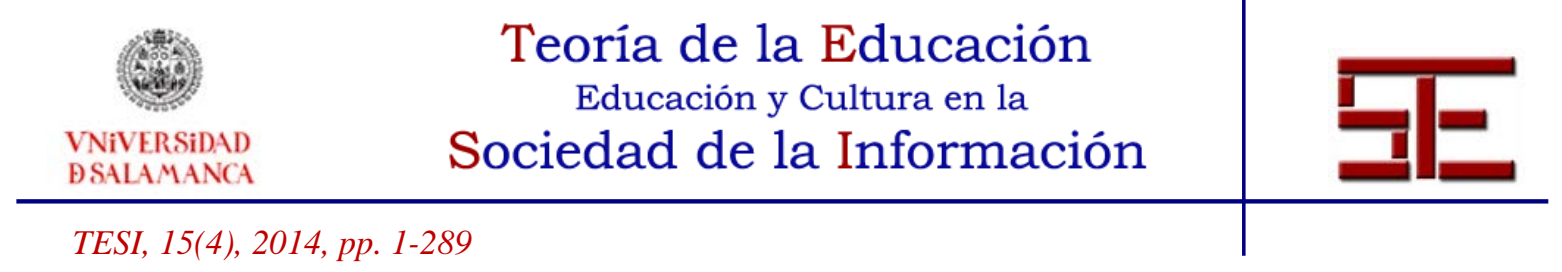

with the problem, and they likely had a simpler time of "making sense" of the problem in their own terms, as it was concerned with 'everyday' or 'common sense' numbers and objects. Students had free reign in creating a solution, and exercised many creative methods in doing so, including drawing diagrams. Because there was less structure, it is feasible that a question like this would lead to more mistakes and a larger proportion of invalid responses. But because responses could be evaluated by their viability, students found more paths toward successful solution. This question constituted a productive exercise for students, one that allowed them to personally "make sense" of the solution by verifying it against visual observations and personal experience.

Students' struggle with Question 3 demonstrates the opposite. The measurements for the thickness of paper and the individual atoms of its composition were, by necessity, stated in scientific notation. Students could not "make sense" of these numbers in a personal way or apply knowledge from previous experiences. While Question 2 promoted and provided adequate opportunity for constructivist inquiry, Question 3 was purely realist. Students could 'construct' their own ideas or methods about solving the problem, but doing so would cause them to reach an incorrect solution. They couldn't make educated guesses about the solution, although it concerned a common piece of paper, because the scope of the problem was not familiar and the measurements could not be verified using visual observation. This exercise was not productive for students, in the sense that the knowledge of the number of atoms in the thickness of paper was not meaningful to them and was not relevant to their lives outside of the classroom. This is not to argue that gaining the knowledge was useless, or that learning to solve similar problems is useless, or even that the exercise involved a 'bad' or inadequate question. Rather, because students were largely unable to make sense of what the correct answer looked like and/or why it was correct, we conclude that this is perhaps a situation where realist pedagogy represents a more effective method of sharing knowledge.

Constructivist pedagogy is most productively applied when students can attach personal meaning to the problem and connect it to their pre-existing knowledge. The problem concerning global warming, Question 1, highlights the bases of students' pre-existing knowledge and describes how a constructivist philosophy of science can shape what students believe about the natural world. Students opposed to taking action on global warming often appealed to science in justifying their belief, but were appealing to a politically, economically, or personally constructed view of reality and to conclusions not supported by the overwhelming majority of experts in the field. From the view of constructivist philosophy, each individual does indeed construct their own view of reality and make their own interpretations of data. But in the case of 'constructing your own reality' about global warming, this involves ignoring decades of work done by professional scientists who have studied the subject extensively, and subjected their work to critical review by other scientists in the field.

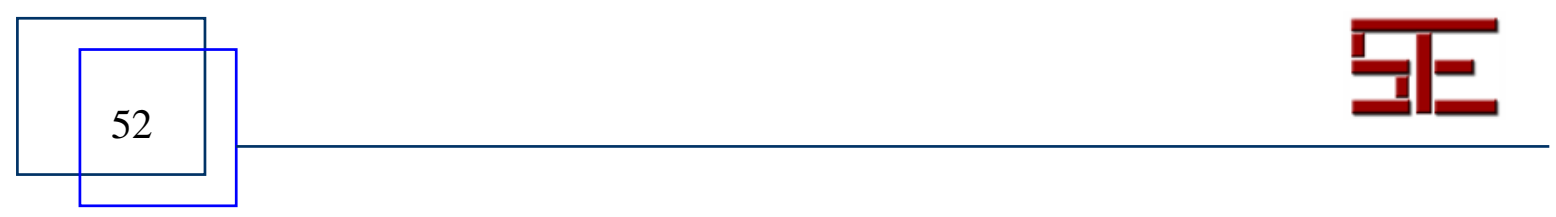




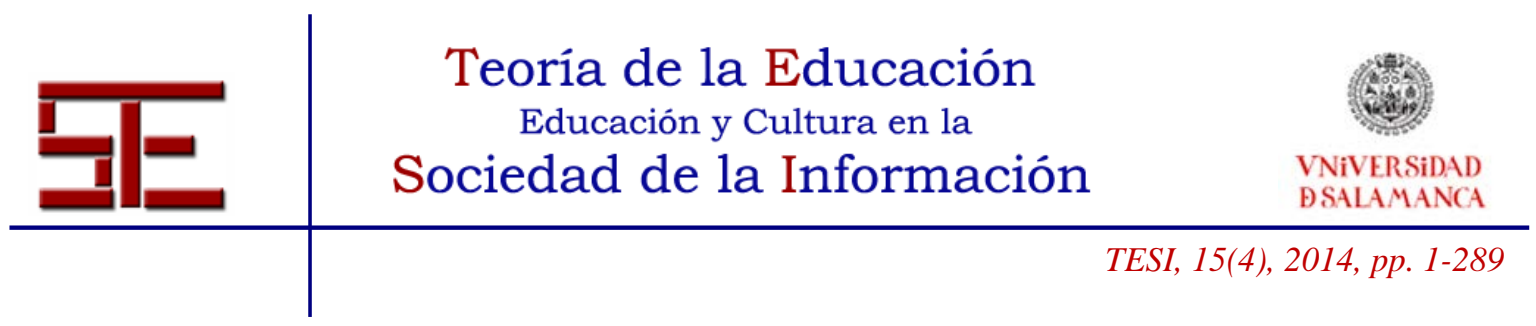

When individuals make their own interpretations of 'science', they typically do not subject their arguments to external falsification: the fact that they believe it to be true is good enough for them and viable for the purpose of their belief. Thus, despite sometimes appealing to the authority of science when constructing their arguments, such individuals are not taking a scientific approach to thinking about the problem. However, in issues of public policy, we must operate on a more rigorous standard; the reality described by your knowledge can't just be good enough for you and your purpose, because it is public policy -it affects all of us. Certainly, basing public policy on falsifiable, peer-reviewed science is the best and most democratic option when making decisions that affect all other inhabitants of your planet.

While there are dangers in not taking a philosophically realist approach to the science used to decide public policy issues such as global warming, it is not productive to take a pedagogically realist approach to educating students on these topics. Students are likely aware of the political, economic, and personal controversies surrounding the existence and causes of global warming, so presenting the issue as being settled conflicts with the observations they may make based on interactions with media, friends/family, or other influential parties. Students need to be presented with some evidence that the scientific consensus is derived from a common, observable reality, and is not just the singular perspective of their teacher or textbook. To this end, we suggest that students could be given the opportunity to 'construct' their own climate graphs. Individually or in groups, they could be directed to sources of historical climate data and $\mathrm{CO}_{2}$ measurements and allowed/required to enter the data points themselves, rather than being presented with premade graphs they might suspect were shaped by a political or personal bias. Alternately, they could be taught methods by which to quantify their personal experiences, or invited to relate their personal experiences with the scientific data.

Future studies could examine changes in students' level of trust in science and in competing pre-existing beliefs. Students could be surveyed about their pre-existing beliefs on a subject, then exposed to scientific data before being re-tested to determine how much effect education had on the state of their knowledge. We suspect that deeply entrenched beliefs cannot be dispelled with exposure to realist scientific data alone, and will require a more constructivist approach. The results of such studies could provide the feedback necessary to create a more effective curriculum and pedagogy, as some cognitive conflicts may be more attached to non-scientific reasoning than others.

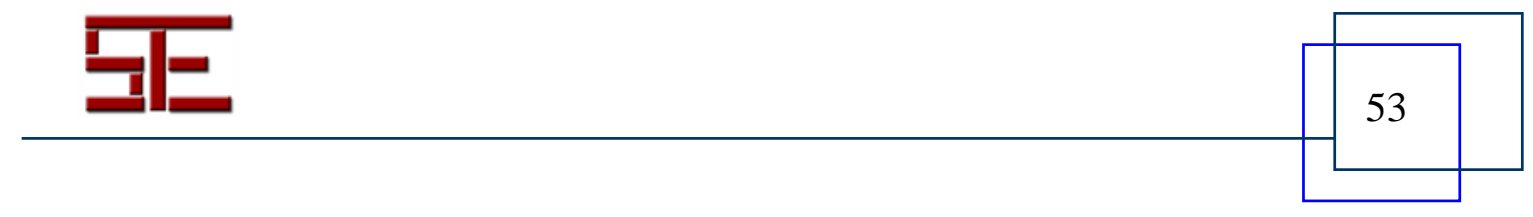




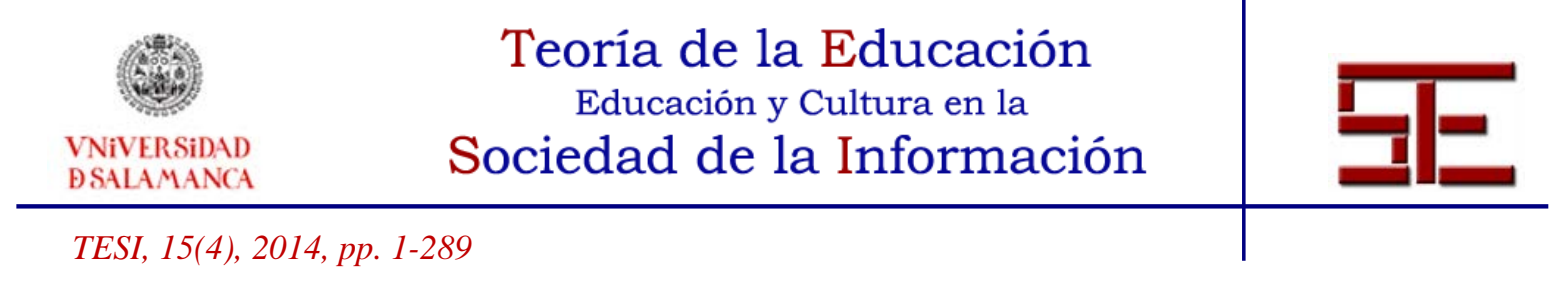

\section{REFERENCES}

Akerlof, K., Maibach, E. W., Fitzgerald, D., Cedeno, A. Y., \& Neuman, A. (2013). Do people "personally experience" global warming, and if so how, and does it matter? Global Environmental Change, 23 (1), 81-91.

Borick, C. P., \& Rabe, B. G. (2010). A reason to believe: examining the factors that determine individual views on global warming. Social Science Quarterly, 91 (3), 777800.

Cole, P. G. (1997). Constructivism and scientific realism? Which is the better framework for educational research. Australian Journal of Teacher Education, 22 (1), 41-49.

Egan, P. J., \& Mullin, M. (2012). Turning personal experience into political attitudes: the effect of local weather on Americans' perceptions about global warming. The Journal of Politics, 74 (3), 796-809.

Feinberg, M., \& Willer, R. (2011). Apocalypse soon? Dire messages reduce belief in global warming by contradicting just-world beliefs. Psychological Science, 22 (1), 3438.

Gil-Pérez, D. et al. (2002). Defending constructivism in science education. Science \& Education, 11 (6), 557-571.

Hutchison, P. \& Hammer, D. (2010). Attending to student epistemological framing in a science classroom. Science Education, 94 (3), 506-524.

Hoogland, K., Bakker, A., De Koning, J., \& Gravemeijer, K. (2012, July). Comparing students' results on word problems with their results on image-rich numeracy problems. In 12th International Congress on Mathematical Education 8 July-15 July, 2012, COEX, Seoul, Korea.

Irzik, G. \& Nola, R. (2011). A Family Resemblance Approach to the Nature of Science for Science Education. Science \& Education, 20 (17), 591-607.

Jenkins, E. W. (2000). Constructivism in school science education: Powerful model or the most dangerous intellectual tendency? Science \& Education, 9 (6), 599-610.

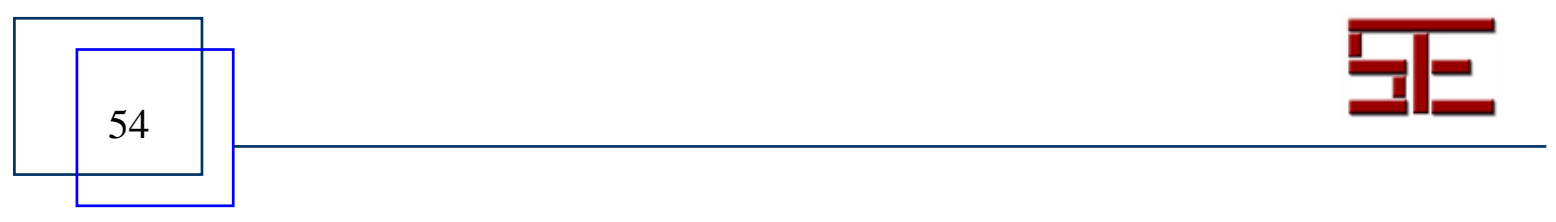




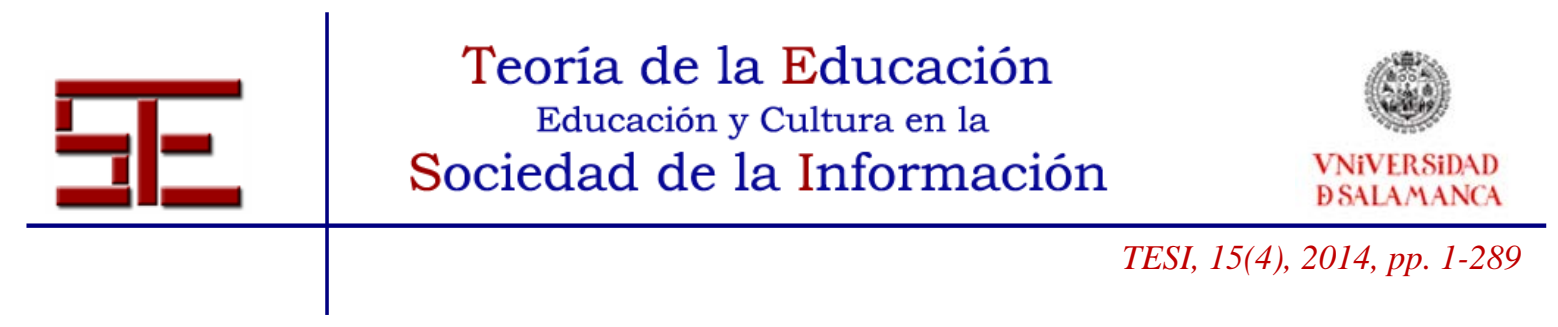

Joireman, J., Barnes Truelove, H., \& Duell, B. (2010). Effect of outdoor temperature, heat primes and anchoring on belief in global warming. Journal of Environmental Psychology, 30 (4), 358-367.

Kaufman, L. March 3, 2010. Darwin foes add warming to targets. The New York Times. Recovered September $21^{\text {st. }}$ http://www.nytimes.com/2010/03/04/science/earth/04climate.html?_r=1

Koul, R. (2003). The relevance of public image of science in science education policy and practice. Science \& Education, 12 (1), 115-124.

McCarthy, C. \& Sears, E. (2000). Science education: Constructing a true view of the real world? In Philosophy of Education 2000, 369-377.

Myers, T. A., Maibach, E. W., Roser-Renouf, C., Akerlof, K., \& Leiserowitz, A. A. (2013). The relationship between personal experience and belief in the reality of global warming. Nature Climate Change, 3 (4), 343-347.

National Center for Education Statistics. (2012). The Nation's Report Card: Science 2011. Washington, DC: Institute of Education Sciences, U.S. Department of Education.

Nola, R. (1997). Constructivism in science and science education: A philosophical critique. Science \& Education, 6 (1), 55-83.

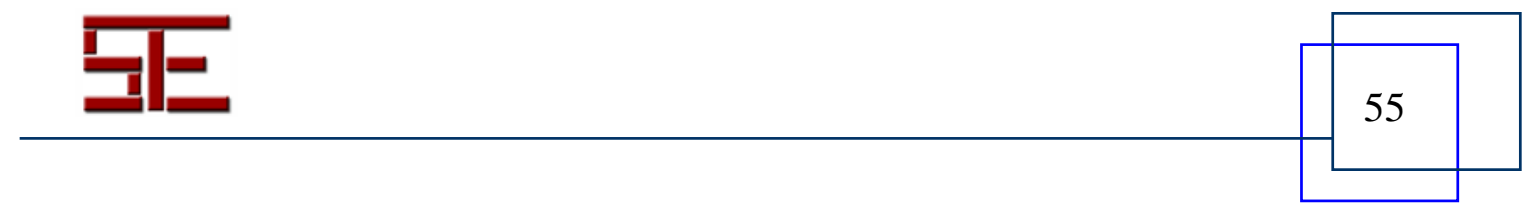

